\title{
Percutaneous renal denervation for the treatment of resistant essential hypertension; the first Dutch experience
}

\author{
M. Voskuil • W. L. Verloop • P. J. Blankestijn • \\ P. Agostoni $\cdot$ P. R. Stella $\cdot$ P. A. Doevendans
}

Published online: 13 May 2011

(C) The Author(s) 2011. This article is published with open access at Springerlink.com

\begin{abstract}
Background In a subpopulation of patients with essential hypertension, therapeutic targets are not met, despite the use of multiple types of medication. In this paper we describe our first experience with a novel percutaneous treatment modality using renal artery radiofrequency $(\mathrm{RF})$ ablation.

Methods Patients who were resistant to at least three types of antihypertensive medical therapy (office systolic blood pressure $\geq 160 \mathrm{mmHg} ; n=9)$ or who did not tolerate medication $(n=2)$ were selected. Between July and November 2010, a total of 11 patients received percutaneous RF treatment. Patients were followed up for 1 month after treatment. Urine and blood samples were taken to evaluate the effects on renal function and neurohumeral factors.

Results No periprocedural complications or adverse events during follow-up were noted. A reduction of mean office blood pressure was seen from 203/109 $\pm 32 / 19 \mathrm{mmHg}$ at baseline to $178 / 97 \pm 28 / 21 \mathrm{mmHg}$ at 1 month follow-up (mean difference $25 \pm 12 \mathrm{mmHg}, p<0.01$ ). Also, we noted a significant decrease in aldosterone level $(391 \pm 210 \mathrm{pmol} / \mathrm{L}$ versus $250 \pm 142 \mathrm{pmol} / \mathrm{L} ; p=0.03)$, while there was no decrease in plasma renin activity $(190 \pm 134 \mathrm{fmol} / \mathrm{L} / \mathrm{s}$ versus $195 \pm 163 \mathrm{fmol} / \mathrm{L} / \mathrm{s} ; p=0.43)$. No change in renal function was noted.

Conclusion Catheter-based renal denervation seems an
\end{abstract}

M. Voskuil $(\bowtie) \cdot$ W. L. Verloop · P. Agostoni · P. R. Stella

P. A. Doevendans

Department of Cardiology, University Medical Center Utrecht,

Room E.01.207, Heidelberglaan 100,

3584 CX Utrecht, the Netherlands

e-mail: m.voskuil@umcutrecht.nl

P. J. Blankestijn

Department of Nephrology, University Medical Center Utrecht,

Utrecht, the Netherlands attractive novel minimally invasive treatment option in patients with resistant hypertension, with a low risk of serious adverse events.

Keywords Hypertension · Percutaneous · Radiofrequency ablation $\cdot$ Neurohumeral

\section{Background}

Using the World Health Organisation criteria of 2001 (systolic blood pressure $\geq 140 \mathrm{mmHg}$ and/or a diastolic blood pressure $\geq 90 \mathrm{mmHg}$ ), $34 \%$ of adult men and $30 \%$ of women in the Netherlands suffer from hypertension [1]. This prevalence increases strongly with age in both men and women.

Treatment of hypertension remains suboptimal. Despite the availability of numerous safe and effective pharmacological therapies, the percentage of patients achieving adequate blood pressure control to guideline target values remains inadequate. The Julius Centre for Health Sciences and Primary Care in Utrecht recently reported that among patients with hypertension, only $33.7 \%$ were aware of the condition. Of those aware patients, only $59.4 \%$ were treated. Of those patients treated, $41.9 \%$ had blood pressure at or below the advised level [2]. Frequent failure of the pharmacological strategy to attain adequate blood pressure control can be attributed to both physicians' negligence as well as patient non-compliance to a lifelong pharmacological therapy for a mainly asymptomatic disease. Thus, the development of new approaches for the management of hypertension, especially those that could help overcome these issues, is a priority. These considerations are especially relevant to patients with drug-resistant hypertension and/or patients with severe intolerance to medication. 
The exact prevalence of therapy-resistant hypertension is not exactly known, but cross-sectional studies suggest that it affects approximately $10-15 \%$ of patients being treated for hypertension by primary care physicians [3].

Renal sympathetic efferent and afferent nerves, which lie within and immediately adjacent to the wall of the renal artery, are crucial for initiation and maintenance of systemic hypertension. Radical surgical methods for sympathetic denervation have been successful in lowering blood pressure in severely hypertensive patients. However, these methods were associated with high perioperative morbidity and even mortality and also long-term complications [4]. Recently, a percutaneous, catheter-based approach using radiofrequency energy (RF) was developed to disrupt renal sympathetic nerves. This resulted in no severe (long-term) vascular or renal injury. Importantly, catheter-based renal nerve ablation was associated with a significant reduction in both systolic and diastolic blood pressure on top of maximal medical therapy, which persisted throughout 12 months follow-up in the first-in-man study [5]. The Symplicity HTN-2 Trial was recently published, which was the first randomised controlled study using this technique of renal denervation, confirming the findings of the first-inman study [6].

Here, we report the results of the first Dutch experience regarding this novel treatment modality.

\section{Methods}

Patient group

Patients were eligible if they have an office systolic blood pressure of $160 \mathrm{mmHg}$ or more, despite being treated with at least three antihypertensive drugs, or confirmed intolerance to medication. Blood pressure measurements were performed in a seated position in at least two subsequent visits in both arms. Blood pressure check was performed before intervention and at 1 month follow-up.

Also, renal function and changes in neurohumeral factors were obtained during follow-up.

The renal artery anatomy was considered suitable in case of a vessel diameter of $\geq 4 \mathrm{~mm}$, no prior renal angioplasty/ stenting and no significant stenosis or other abnormalities.

Exclusion criteria for this treatment modality were pregnancy, age below 18 years, patients with any known secondary cause of hypertension and a glomerular filtration rate estimated at $<45 \mathrm{~mL} / \mathrm{min} / 1.73 \mathrm{~m}^{2}$. Also, patients with type 1 diabetes, haemodynamically significant valvular disease, implantable cardioverter defibrillators, or who are on treatment with clonidine, moxonidine, rilmenidine, or warfarin, were excluded from intervention.
Procedure

Patients were pretreated with diazepam $5 \mathrm{mg}$ and midazolam $1 \mathrm{mg}$. Using local anaesthetics, cannulation of the femoral artery was performed using the standard Seldinger technique. An $8 \mathrm{Fr}$ sheath was introduced and unfractionated heparin was given using an intravenous bolus of $1000 \mathrm{IE} / \mathrm{kg}$ bodyweight with a target activated clotting time $(\mathrm{ACT})>250 \mathrm{~s}$. Using an $8 \mathrm{Fr}$ renal double curve (RDC) or left internal mammary artery (LIMA) renal guiding catheter and a $5 \mathrm{Fr}$ soft tip straight delivery catheter, a steerable catheter with radiofrequency energy electrode tip was delivered into the renal artery. Before treatment, a starting dose of fentanyl $50 \mu \mathrm{g}$ was given. A bilateral treatment of the renal arteries was performed with the use of series of 2minute RF energy deliveries along each artery, aiming at 46 treatment points per artery (approximately 8 Watts of energy per treatment point). These treatment points are made with a minimum of $5 \mathrm{~mm}$ distance in between and with a pullback from distal to proximal in a circumferential way. A control angiography was performed after the procedure. Also, in a subset of three patients, intravascular ultrasound (IVUS) was performed.

\section{Statistical analysis}

Continuous variables are described with mean \pm standard deviation. Dichotomous variables are reported as numbers (percentages). For comparison within different time points, a paired $t$ test was used. A two-sided alpha level of 0.05 was used for superiority testing. All statistical analyses were done with PASW Statistics version 17.0 (IBM SPSS, Somers, NY, USA).

\section{Results}

The baseline characteristics of the patient group are listed in Table 1. The mean time of the procedure (i.e. from puncture of the femoral artery to closure) was $74 \pm 9 \mathrm{~min}$. Mean fluoroscopy time was $15 \pm 2 \mathrm{~min}$. The ACT time achieved was $298 \pm 74 \mathrm{~s}$. The mean use of contrast was $208 \pm 35 \mathrm{ml}$. A mean dose of fentanyl of $164 \pm 29 \mu \mathrm{g}$ was given (including the starting dose of $50 \mu \mathrm{g}$ ). For midazolam the mean periprocedural dose was $3 \pm 1.4 \mathrm{mg}$ (including the starting dose of $1 \mathrm{mg}$ ). In total, an average of $5.1 \pm 1 \mathrm{RF}$ ablations were performed in the left renal artery, and 5.6 $1 \mathrm{RF}$ ablations in the right renal artery.

No patients showed endovascular damage at final angiography. In a small subgroup IVUS was performed, which showed no dissections or other intravascular complications $(n=3)$. 
Table 1 Baseline characteristics of the patients $(n=11)$

\begin{tabular}{ll}
\hline Age (years) & $68 \pm 12$ \\
Sex (female) & $10(91)$ \\
Race (Caucasian) & $11(100 \%)$ \\
Weight (kg) & $82 \pm 20$ \\
Length (cm) & $165 \pm 11$ \\
Body mass index & $30 \pm 8$ \\
Medical history & \\
- CAD & $5(45 \%)$ \\
- CVA/TIA & $2(18 \%)$ \\
- Diabetes & $2(18 \%)$ \\
- Hypercholesterolaemia & $4(36 \%)$ \\
Baseline SBP (mmHg) & $203 \pm 32$ \\
Baseline DBP (mmHg) & $109 \pm 19$ \\
Number of antihypertensive medications & $3.1 \pm 1.5$ \\
Patients on medication & \\
- Beta blockers & $8(73 \%)$ \\
- ACE inhibitors/ARBs & $9(82 \%)$ \\
- Calcium channel blockers & $3(27 \%$ \\
- Vasodilators & $2(18 \%)$ \\
- Diuretics & $5(45 \%)$ \\
- Renin blocker & $2(18 \%)$ \\
- Alpha blockers & $2(18 \%)$ \\
eGrum creatinine ( $\mu$ mol/L) & $78 \pm 17$ \\
\hline
\end{tabular}

$A C E$ angiotensin-converting enzyme, ARB angiotensin receptor blocker, CVA cerebrovascular accident, DBP diastolic blood pressure, GFR glomerular filtration rate, SBP systolic blood pressure, TIA transient ischaemic attack

After the procedure, there was no change in serum creatinine $(78 \pm 17 \mu \mathrm{mol} / \mathrm{L}$ before compared with $78 \pm$ $16 \mu \mathrm{mol} / \mathrm{L} ; p=0.92)$. There was a statistically significant, but clinically not relevant, drop in haemoglobin of $9.0 \pm$ $0.7 \mathrm{mmol} / \mathrm{L}$ to $8.6 \pm 0.7 \mathrm{mmol} / \mathrm{L} ; p<0.01)$. In general, there were no periprocedural (particularly access site) complications and/or complications during follow-up. No changes in medication were noted at 1-month follow-up.

As depicted in Fig. 1, the systolic office blood pressure decreased from $203 \pm 32 \mathrm{mmHg}$ at baseline to $178 \pm$ $28 \mathrm{mmHg}$ at 1 month follow-up. This is a decrease of 25 $\pm 12 \mathrm{mmHg}(p<0.01)$. The diastolic blood pressure changed from $109 \pm 19 \mathrm{mmHg}$ at baseline to $97 \pm 21 \mathrm{mmHg}$ at follow-up (decrease of $12 \pm 11 \mathrm{mmHg} ; p<0.01$ ).

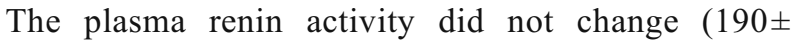
$134 \mathrm{fmol} / \mathrm{L} / \mathrm{s}$ versus $195 \pm 163 \mathrm{fmol} / \mathrm{L} / \mathrm{s} ; p=0.43)$. Interestingly, there was a decrease in aldosterone level (391 \pm $210 \mathrm{pmol} / \mathrm{L}$ versus $250 \pm 142 \mathrm{pmol} / \mathrm{L} ; p=0.03)$. In urine samples taken before and 1 month after the procedure, no significant decrease in microalbuminuria $(39 \pm 80 \mathrm{mg} / \mathrm{L}$ versus $27 \pm 55 \mathrm{mg} / \mathrm{L} ; p=0.22$ ) and total amount of protein

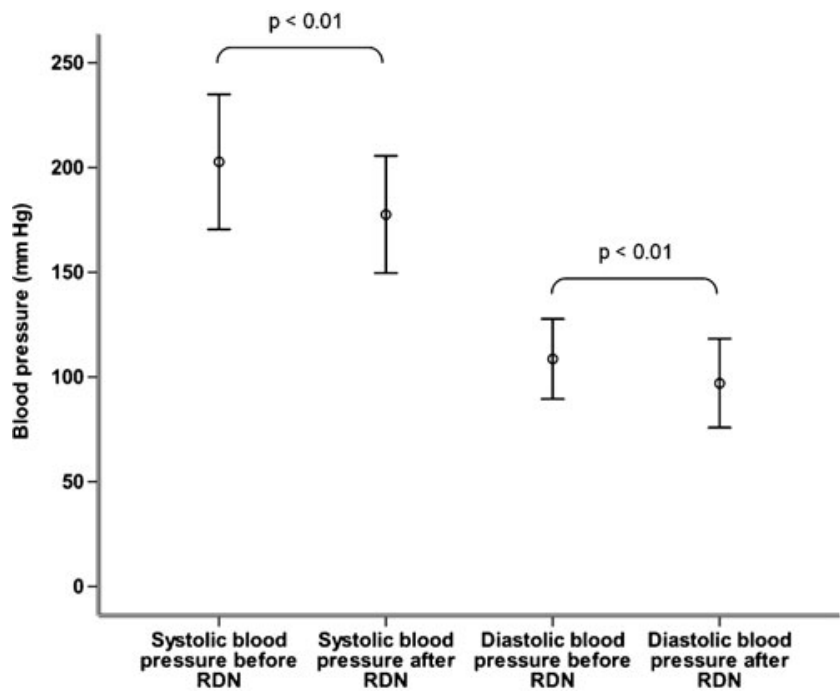

Fig. 1 Mean systolic and diastolic blood pressure before and after renal denervation $(\mathrm{RDN})$

in the urine was noted $(0.14 \pm 0.10 \mathrm{~g} / \mathrm{L}$ versus $0.13 \pm 0.07 \mathrm{~g} /$ $\mathrm{L} ; p=0.35$ ).

\section{Discussion}

Our first experience with renal sympathetic denervation, using a percutaneous approach, confirms the results of the previous proof-of-principle and recent randomised study, showing the safety and efficacy of this new treatment modality in daily clinical practice for patients with therapyresistant hypertension $[5,6]$.

The decrease of blood pressure achieved in our patient population is comparable with that achieved in the previous studies and most likely will be clinically relevant, although current guideline target values were not met in our patients with extreme hypertension (baseline blood pressure 200/ $106 \mathrm{mmHg}$ )[7]. A recent meta-analysis by Law et al. showed that irrespective of the type of medication used, the incidence of coronary heart disease events was reduced by $22 \%$ after a systolic blood pressure reduction of $10 \mathrm{mmHg}$ or a diastolic blood pressure reduction of $5 \mathrm{mmHg}$. Even more, the incidence of stroke was reduced by $41 \%$ [8]. Assuming that the effects of renal denervation are as effective in reducing clinical events as a pharmacological approach for the treatment of hypertension, the observed blood pressure reduction of $25 / 12 \mathrm{mmHg}$ in our patients will most likely be highly beneficial.

The efficacy of this new treatment option should not only be present in the short term, but particularly during long-term follow-up. Several patients treated with this new technique are now approaching the 2-year follow-up, and the blood pressure reductions observed appear to be sustained over this period, 
suggesting the absence of nerve fibre recovery, nerve fibre regrowth, or development of counter-regulatory blood pressure-elevating mechanisms [9].

Besides efficacy, safety remains an equally important issue in a therapy for (secondary) prevention of disease. No adverse events were noted in our first patients periprocedurally and/or at follow-up. In the first cohort study performed in a multicentre setting, no renal artery stenosis occurred as verified using follow-up renal magnetic resonance angiogram at 6 months [5]. Among all patients treated worldwide, a local dissection without sequelae was noted during the procedure in 2 patients, a few access site bleedings were reported, but no (long-term) side effects have been published up till now [6]. Particularly, no change in renal function has been noted.

There is accumulating preclinical and clinical evidence compelling for a primary role of renal sympathetic activation in the pathogenesis of hypertension as described in recent review articles $[10,11]$. A crosstalk between the central nervous system and the kidneys is present (Fig. 2). Blocking sympathetic nerves leading to the kidney ('efferent') will reverse fluid and salt retention. By blocking sympathetic nerves emanating from the kidney ('afferent'), renal denervation may also decrease the stimulation of other parts of the sympathetic nervous system, such as the heart and blood vessels, leading to an additional antihypertensive effect.

The earliest insight into the influence of intervention of the sympathetic nerve activity on renal function in hypertension is that of Claude Bernard in 1859 [12]. He observed that by cutting the greater splanchnic nerve, he caused an increased diuresis, whereas electrical renal sympathetic nerve stimulation produced a reduced diuresis. However, the surgical approach of (non-specific) renal denervation coincided with severe side effects as observed in studies from the $1930 \mathrm{~s}$ using surgical denervation of the sympathetic system of the thoracico-lumbar region and has therefore been abandoned [13, 14]. Using the catheterbased renal denervation in patients as described in this paper, we may have overcome these side effects of nonspecific denervation of the lumbar region [15].

Pathophysiological proof of concept of the denervation of the renal artery has also been shown in a small subset of patients $[16,17]$. Schlaich et al. demonstrated that the socalled norepinephrine spillover resulted in a decrease of $40-50 \%$, which was accompanied by halving of renin activity and an increase in renal plasma flow. In our population, only a decrease in aldosterone was shown. Most likely, because of the small size of the population, no uniform effects of the intervention could be shown on the neurohumeral level in our population. Moreover, it was shown that microneurography at baseline and at follow-up showed a reduction in muscle sympathetic-nerve activity to normal levels [17].

For future therapeutic application of sympathetic denervation of the renal arteries, further research is needed to identify groups of patients who might benefit from this intervention. In this light, searching for efficacy in patients with, for instance, chronic kidney disease, patients with heart failure, diabetes and obesity will be interesting. Also, studies in milder forms of essential hypertension should be the next goal of research using this percutaneous technique. Hereby, hard endpoint studies are warranted to prove the value of this new percutaneous technique in daily clinical practice.
Fig. 2 Schematic representation of the involvement of sympathetic hyperactivity in the pathogenesis of hypertension. Increased plasma levels of angiotensin II and/or increased afferent renal nerve activity stimulates the central nervous system to increase central sympathetic outflow

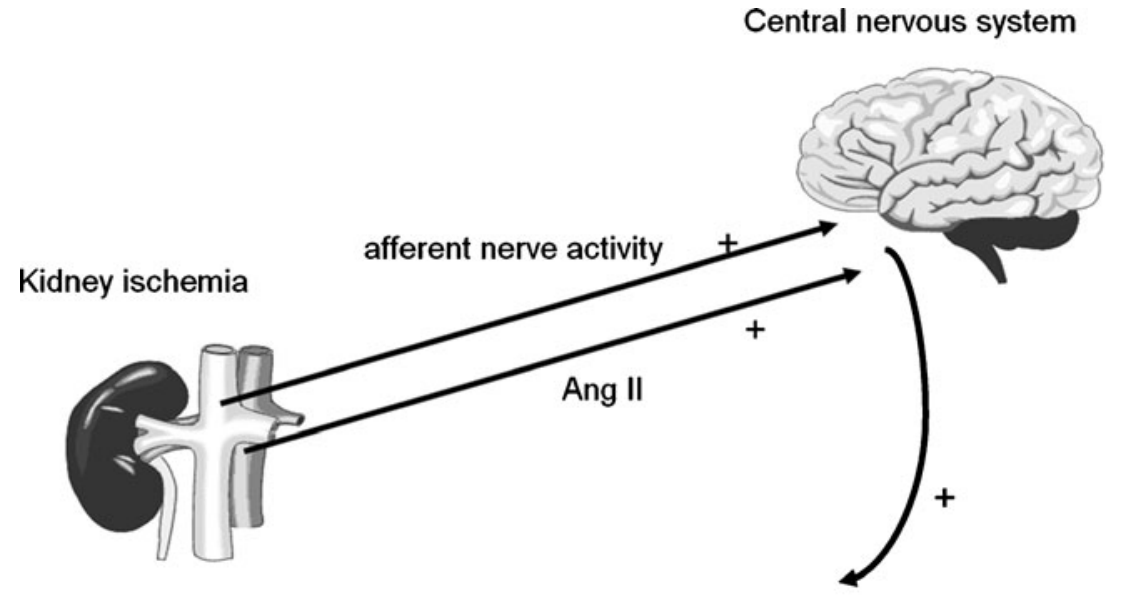

sympathetic activity

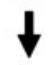

Effects on cardiovascular system, kidneys and other 
Acknowledgments We thank the nurses of the Department of Cardiac Catheterization for their cooperation. Especially, Mathilde Hissink and Marijke van der Linde have contributed to the success of implementation of the program.

Open Access This article is distributed under the terms of the Creative Commons Attribution Noncommercial License which permits any noncommercial use, distribution, and reproduction in any medium, provided the original author(s) and source are credited.

\section{References}

1. Vliet AL, van den Hof S, Elvers LH, et al. Risicofactoren en gezondheidsevaluatie Nederlandse bevolking, een onderzoek op GGD'en (Regenboogproject). Jaarverslag 2001. RIVM rapport $260854004 / 2003$.

2. Scheltens T, Bots ML, Numans ME, et al. Awareness, treatment and control of hypertension: the 'rule of halves' in an era of risk-based treatment of hypertension. J Hum Hypertens. 2007;21(2):99-106.

3. Egan BM, Zhao Y, Rehman SU, et al. Treatment resistant hypertension in a community-based practice network. J Clin Hypertens 2009; OR-12:A6; (abstract).

4. Morrissey DM, Brookes VS, Cooke WT. Sympathectomy in the treatment of hypertension; review of 122 cases. Lancet. 1953;1 (6757):403-8.

5. Krum H, Schlaich M, Whitbourn R, et al. Catheter-based renal sympathetic denervation for resistant hypertension: a multicentre safety and proof-of-principle cohort study. Lancet. 2009;373 (9671):1275-81.

6. Esler MD, et al on behalf of the Symplicity HTN-2 Investigators. Renal sympathetic denervation in patients with treatment resistant hypertension (The Symplicity HTN-2 Trial): a randomised controlled trial. Published Online November 17, 2010. doi:10.1016/S0140-6736(10)62039-9.
7. 2007 Guidelines for the Management of Arterial Hypertension: The Task Force for the Management of Arterial Hypertension of the European Society of Hypertension (ESH) and of the European Society of Cardiology (ESC). J Hypertens 2007;25 (6):1105-87.

8. Law MR, Morris JK, Wald NJ. Use of blood pressure lowering drugs in the prevention of cardiovascular disease: meta-analysis of 147 randomised trials in the context of expectations from prospective epidemiological studies. BMJ. 2009;338:b1665.

9. Schlaich MP, Krum H, Sobotka PA. Renal sympathetic nerve ablation: the new frontier in the treatment of hypertension. Curr Hypertens Rep. 2010;12:39-46.

10. DiBona GF, Esler M. Translational medicine: the antihypertensive effect of renal denervation. Am J Physiol Regul Integr Comp Physiol. 2010;298(2):R245-53.

11. Siddiqi L, Joles JA, Grassi G, et al. Is kidney ischemia the central mechanism in parallel activation of the renin and sympathetic system? J Hypertens. 2009;27:1341-9.

12. Bernard C. Lec, ons sur les Proprie'te's et les Alte'rations Pathologiques des Liquides de L'Organisme, vol. 2. Paris: Baillie're et Fils; 1859. p. 170-1.

13. Page IH, Heuer GJ. A surgical treatment of essential hypertension. J Clin Invest. 1935;14(1):22-6.

14. Adson AW, Brown GE. Malignant hypertension. Report of case treated by bilateral section of anterior spinal nerve roots from the sixth thoracic to the second lumbar inclusive. JAMA. 1934; $102: 1115$.

15. Schlaich MP, Sobotka PA, Krum H, et al. Renal denervation as a therapeutic approach for hypertension: novel implications for an old concept. Hypertension. 2009;54(6):1195-201.

16. Schlaich MP, Sobotka PA, Krum H, et al. Renal sympatheticnerve ablation for uncontrolled hypertension. N Engl J Med. 2009;361(9):932-4.

17. Krum H. Is hypertension the next frontier for interventional therapy? Transcatheter Cardiovascular Therapeutics 2010. 